This is a peer-reviewed, accepted author manuscript of the following article: Azat, S., Korobeinyk, A. V., Moustakas, K., \& Inglezakis, V. J. (2019). Sustainable production of pure silica from rice husk waste in Kazakhstan. Journal of Cleaner

Production, 217, 352-359. https://doi.org/10.1016/i.jclepro.2019.01.142

\title{
Sustainable production of pure silica from rice husk waste in Kazakhstan
}

\author{
S. Azat ${ }^{\mathrm{a}, \mathrm{b}}$, A.V. Korobeinyk ${ }^{\mathrm{a}, \mathrm{c}}$, K. Moustakas ${ }^{\mathrm{d}}$, V.J. Inglezakis ${ }^{\mathrm{a}, \mathrm{e}^{*}}$

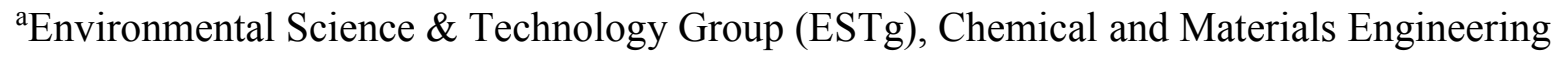 \\ Department, School of Engineering, Nazarbayev University, Kabanbay Batyr, Ave. 53, \\ Astana, Kazakhstan \\ bal-Farabi Kazakh National University, Almaty, Kazakhstan \\ ${ }^{c}$ O.O. Chuiko Institute of Surface Chemistry of NAS of Ukraine, Kyiv, Ukraine \\ ${ }^{\mathrm{d}}$ School of Chemical Engineering, National Technical University of Athens, 9 Heroon \\ Polytechniou Street, Zographou Campus, Athens, Greece \\ ${ }^{\mathrm{e}}$ The Environment and Resource Efficiency Cluster, Nazarbayev University, Kabanbay \\ Batyr, Ave. 53, Astana, Kazakhstan
}

*Corresponding author: vasileios.inglezakis@nu.edu.kz

Keywords: rice husk; rice husk ash; white rice husk; silica; agricultural waste;

\section{Research highlights:}

- Rice husk - an agricultural waste was successfully converted into pure amorphous silica;

- Three different locally grown samples of rice hull were utilized for silica extraction; 
- Three different methods for the production of silica from rice husks were investigated;

- A greener and more economic method gave promising results.

\begin{abstract}
This study aimed at developing a new synthesis method for the production of high purity silica from rice husks originated from different regions of Kazakhstan. A novel ecofriendly method is compared with the conventional one reported in the literature which is accompanied by the use of significant amount of inorganic alkali and acids and direct combustion. In order to reduce the environmental impact, the mineral acid pre-treatment stage was either removed or replaced with organic acid pre-treatment, which reduced the amount of chemicals used during the synthesis and treatment process. The calcination temperature of $600^{\circ} \mathrm{C}$ was selected based on thermogravimetric analysis. The average purity of silica samples obtained via different methods ranged from 84.81 to $99.66 \mathrm{wt} . \%$. The purity of the produced silica by use of the greener method was high reaching $98.67 \%$ with surface area up to $625 \mathrm{~m}^{2} / \mathrm{g}$.
\end{abstract}

\title{
1. Introduction
}

Rice is the second largest cereal crop in the world. According to data published by the Food and Agriculture Organization (FAO) the world rice production in 2016 was $748 \times 10^{6} \mathrm{t}$, while in Kazakhstan the production amounted to $291 \times 10^{3}$ t. Rice-growing employs more than $50 \%$ of the labor resources in the agricultural sector of the world economy and the consumers' demand for rice increases every year. According to the projections of the FAO, by 2020 the demand will be $781 \times 10^{6} \mathrm{t}$ and will exceed the demand for wheat by $2-3 \%$. Rice growing in Kazakhstan is developed mainly in the south, in the areas of the lower reaches of 
the Syr Darya River, in the territory of the Kyzylorda Region. According to the Ministry of Agriculture of the Republic of Kazakhstan, the main regions involved in rice production are the Kyzylorda Region $\left(784 \times 10^{6} \mathrm{~m}^{2}\right)$, Almaty Region $\left(111 \times 10^{6} \mathrm{~m}^{2}\right)$ and South Kazakhstan Region $\left(30 \times 10^{6} \mathrm{~m}^{2}\right)$.

Rice husk (RH) is an agricultural waste stream that is abundant in agro-based countries, such as China, India, Bangladesh, Brazil, USA and Kazakhstan. The rice grain consists of about 20 wt.\% of $\mathrm{RH}$. RH constitutes a waste problem in rice-producing regions and the increase of the areas of rice cultivation requires the development of new approaches to the RH management (Santana Costa and Paranhos, 2018). The estimated production of waste RH in Kazakhstan is about $64 \times 10^{3}$ t.

The management of $\mathrm{RH}$ is an important and multifactor issue, while recycling and utilization should be the main target. Traditionally RH has been either burned or disposed of in landfills, but environmental regulations limited this practice. Nevertheless, burning in open air is still practiced especially in poor and developing countries causing environmental and health problems (Memon et al., 2011). The combustion of RH as fuel substitute for power generation is a solution that is used in many fields of industry; however, this produces a new waste stream known as rice husk ash. Due to its high silica content, rice husk is considered as an economically viable raw material for the production of silicates and silica materials. $\mathrm{RH}$ has been utilized in several sectors as construction material in a concrete production (Sandhu and Siddique, 2017), fuel in power plants (Prasara and Gheewala, 2018) for the synthesis of activated carbon (Liu et al., 2012) and as adsorbent for the removal of organic dyes (Franco et al., 2017), phosphates (Mor et al., 2016) and heavy metals from wastewater (Feng et al., 2004).

$\mathrm{RH}$ is characterized by negligible nutritional value, chemical-physical resistance, low bulk density and high ash content. The main constituents of the husks are organic compounds 
(about 75\% cellulose, hemi-cellulose and lignin) and silica (about 15\%) (Alyosef et al., 2013). Silica is the major mineral component of RH ash which also contains potassium, sodium, magnesium, calcium, iron, phosphorus and much smaller quantities of other elements (Bakar et al., 2016). The composition variation of the RH and RH ash is caused by several factors, such as the agricultural practices applied (amount and type of fertilizers used) and climatic or geographical factors, as shown in Table 1 (Ugheoke and Mamat, 2012).

\section{Table 1}

Elemental composition of the RH ash by geographical locations

\begin{tabular}{|c|c|c|c|c|c|c|}
\hline \multirow{3}{*}{ Composition } & \multicolumn{3}{|c|}{$\mathrm{XRF}$} & \multirow[t]{2}{*}{$\mathrm{XRF}$} & \multirow[t]{2}{*}{ ICP } & \multirow[t]{2}{*}{ XRF } \\
\hline & & & & & & \\
\hline & \multicolumn{3}{|c|}{ Kazakhstan } & Canada & Egypt & Malaysia \\
\hline $\mathrm{SiO}_{2}$ & $91.39^{*}$ & $92.42^{* *}$ & $91.05^{* * *}$ & 91.56 & 91.5 & 91.25 \\
\hline $\mathrm{K}_{2} \mathrm{O}$ & 1.25 & 1.81 & 1.34 & 4.76 & 1.23 & 3.83 \\
\hline $\mathrm{CaO}$ & 2.62 & 1.32 & 2.84 & 0.78 & 2.57 & 0.88 \\
\hline $\mathrm{SO}_{3}$ & 2.02 & 1.05 & 2.12 & 0.29 & - & 0.66 \\
\hline $\mathrm{P}_{2} \mathrm{O}_{5}$ & - & - & - & - & 2.30 & 2.45 \\
\hline $\mathrm{Al}_{2} \mathrm{O}_{3}$ & 0.23 & 0.45 & 0.15 & 2.36 & 1.46 & 0.18 \\
\hline $\mathrm{MnO}$ & 0.64 & 0.58 & 1.22 & 0.07 & 0.04 & 0.07 \\
\hline $\mathrm{Fe}_{2} \mathrm{O}_{3}$ & 0.57 & 0.64 & 0.50 & 0.11 & 0.42 & 0.09 \\
\hline $\mathrm{Na}_{2} \mathrm{O}$ & 0.36 & - & 0.32 & - & 0.18 & - \\
\hline $\mathrm{MgO}$ & 0.31 & 0.61 & 0.21 & - & 0.30 & 0.57 \\
\hline $\mathrm{CuO}$ & 0.29 & 0.12 & 0.25 & 0.06 & - & - \\
\hline $\mathrm{Cl}$ & 0.28 & 0.52 & - & - & - & - \\
\hline $\mathrm{ZnO}$ & 0.04 & 0.48 & - & 0.01 & - & 0.01 \\
\hline
\end{tabular}


${ }^{*}$ Almaty region, ${ }^{* *}$ Kyzylorda region, ${ }^{* * *}$ South Kazakhstan region

Table 1 shows that although the composition of the $\mathrm{RH}$ ash varies, the silica content is between 91 and 93\%. Because of the high silica content, the RH can be a cost-effective raw material for the production of silicates and silica materials (Kumar et al., 2013). The temperature of calcination (incineration), the holding time and the applied pretreatment methods affect the quality of the resulting silica. Silica produced from $\mathrm{RH}$ at a temperature of 500 to $650^{\circ} \mathrm{C}$ with a combustion time of 2.5 to $6 \mathrm{~h}$ is predominantly amorphous, while crystallinity is achieved when the annealing temperature rises above $700^{\circ} \mathrm{C}$. While crystalline silica is used in ceramics, steel, thermal insulator and refractory bricks (Prasad et al., 2001) and in the concrete industry (Kumar et al., 2013), amorphous silica finds a much wider range of applications in concrete production (Kannan, 2018), pulp industry (Chen et al., 2017), laboratory glassware (Shi et al., 2017), adsorbents (Pivovarov, 2008) and drag delivery carriers (Mitran et al., 2018). Various value-added products, such as aerogel (Tang and Wang, 2005), silica carbide (Niyomwas, 2009), porous carbon (Satayeva et al., 2018), zeolites ( $\mathrm{Ng}$ et al., 2015) and other products can be obtained by using the silica produced from RH (Shen et al., 2014). Therefore, the RH combustion residue can be considered as a cost-effective raw material for the production of silica (Kalapathy et al., 2001). Nevertheless, despite the potential usefulness of the RH as source of several materials, its processing is not always cost-effective or environmentally friendly (Lakshmi et al., 2009). A summary of the available treatment methods of $\mathrm{RH}$ and $\mathrm{RH}$ ash for the production of silica can be found in Fernandez et al. (2017) and are typically based on a combination of acid and thermal treatment (Fernandes et al., 2017).

This study aims at investigating new synthesis methods for the production of high purity silica from RH originated from the rice-producing regions of Kazakhstan. A new 
greener method is compared with conventional ones reported in the literature. In order to reduce the environmental impact, the mineral acid pre-treatment stage typically used in the literature (Mor et al., 2017) for the removal of impurities was either removed or replaced with organic acid pre-treatment, which reduces the amount of chemicals used during the synthesis and treatment phase. The alternative synthesis is a dry method, i.e. no citric acid solution was used, differentiating it from wet methods used in previous studies, where $25 \mathrm{ml}$ (Alyosef et al., 2013), 7.5-100 $\mathrm{ml}$ (He et al., 2014) and 16.7-20 ml ( Umeda and Kondoh, 2010, 2008) of citric acid solution per g of RH were used. Also, the economic benefits of such synthetic approaches are discussed.

\section{Materials and Methods}

\subsection{Rice husks}

The RHs were supplied by rice-growing farms of three different rice growing regions of Kazakhstan: RH1-Almaty (Balkhash district, rice variety - Regul), RH2-Kyzylorda (Syrdarya district, rice variety - Lider) and RH3-South Kazakhstan (Zhetysay, rice variety 42). All obtained RHs were washed with deionized water to remove soluble contaminants, air dried in fume hood overnight in order to prevent steaming during the oven drying and finally dried in bench oven (Carbolite, PF 300, Keison, UK) for $8 \mathrm{~h}$ at $105{ }^{\circ} \mathrm{C}$. Washed and dried RHs were stored in polyethylene zip-lock bags at room temperature until use.

\subsection{Acid treatment}

Acid pre-treatment delignifies $\mathrm{RH}$ and improves subsequent calcination via loosening of its rigid structure. The acid pre-treatment of $\mathrm{RH}$ was performed according to Ang et al. (Ang et al., 2013) using glass reactor, $2 \mathrm{M} \mathrm{HCl}$ at $10 \%(\mathrm{w} / \mathrm{v}) \mathrm{RH}$ loading, $90{ }^{\circ} \mathrm{C}$ and continuous stirring for $2 \mathrm{~h}$. After pre-treatment with $\mathrm{HCl}$, the $\mathrm{RH}$ samples were washed with 
deionized water to $\mathrm{pH} 7$ and dried at $105^{\circ} \mathrm{C}$ for $8 \mathrm{~h}$. The citric acid pre-treatment was carried out in a ceramic crucible by mixing $50 \mathrm{~g}$ of $\mathrm{RH}$ (washed and dried) and citric acid at the acid $/ \mathrm{RH}$ ratio of $100 \mathrm{~g} / \mathrm{kg}$. The crucible is placed in the furnace for calcination. The method used is dry compared to wet methods used by Alyosef et al. (Alyosef et al., 2013), who mixed $40 \mathrm{~g} \mathrm{RH}$ with $1,000 \mathrm{ml}$ of $5 \%$ citric acid solution at $80^{\circ} \mathrm{C}$, He et al. (He et al., 2014), who mixed $4 \mathrm{~g}$ RH with $30-100 \mathrm{ml}$ of citric acid solution at $\mathrm{pH} 2.5$ and $80^{\circ} \mathrm{C}$, Umeda and Kondoh (Umeda and Kondoh, 2008), who mixed 20g RH with $500 \mathrm{ml}$ of 5\% citric acid solution at $50^{\circ} \mathrm{C}$, and Umeda and Kondoh (Umeda and Kondoh, 2010), who mixed 30g RH with $500 \mathrm{ml}$ of $1-7 \%$ citric acid solution at $80^{\circ} \mathrm{C}$.

\subsection{Calcination}

Based on the experimental data obtained by a preliminary TGA analysis, the calcination temperature of $600^{\circ} \mathrm{C}$ was chosen. The washed and dried husks were calcined in air for $4 \mathrm{~h}$ using a ceramic crucible and a thermocouple equipped muffle furnace (Carbolite, CWF 1200, Keison, UK). Each crucible was loaded with $50 \mathrm{~g}$ of RHs. White rice husk (WRH) ashes were collected and used for pure silica extraction. The same calcination procedure was applied to $\mathrm{RH}$ pre-treated with $\mathrm{HCl}$ (conventional method) and citric acid (CA). 




Fig.1. Scheme RH treatment methods.

According to the synthesis procedure, the following notation is used:

- directly incinerated samples are denoted as RHT1-3 and silica samples produced from their WRHs denoted as $\mathrm{SiO}_{2} \mathrm{~T} 1-3$;

- $\mathrm{HCl}$ pre-treated samples denoted as $\mathrm{RH} \_\mathrm{A} 1-3\left(\mathrm{SiO}_{2} \_\mathrm{A} 1-3\right)$ and citric acid pretreated samples as RH_CA1-3 $\left(\mathrm{SiO}_{2} \_\mathrm{CA} 1-3\right)$.

\subsection{Silica extraction}

WRH collected after calcination was mixed with $100 \mathrm{ml}$ of $2 \mathrm{M} \mathrm{NaOH}$ at $90^{\circ} \mathrm{C}$ under continuous vigorous stirring for $2 \mathrm{~h}$ in order to convert the solid silica into water-soluble sodium silicate (SS). The SS solution was filtered through cellulose membrane filter (Millipore, $0.45 \mu \mathrm{m}$ ) in order to remove insoluble residues and carbonizates (black ashes). SS was then converted into insoluble silicic acid via titration with $2 \mathrm{M} \mathrm{HCl}$ under continuous 
stirring. The final product was washed with hot deionized water to $\mathrm{pH} 7$ and then dried in a bench oven for $4 \mathrm{~h}$ at $105^{\circ} \mathrm{C}$.

\subsection{Characterization}

Thermal analysis was conducted using a Perkin Elmer STA 6000 with a heating rate $10^{\circ} \mathrm{C} \cdot \mathrm{min}^{-1}$ in a temperature range from 50 to $950^{\circ} \mathrm{C}$ under nitrogen atmosphere. X-ray diffraction (XRD) patterns were recorded using Rigaku (SmartLab ${ }^{\circledR}$ X-ray) diffraction system with $\mathrm{Cu} \mathrm{K \alpha}$ radiation source $(\lambda=1.540056 \AA)$ at a scan rate of $0.02^{\circ} \theta \cdot \mathrm{s}^{-1}$ in the $2 \theta$ range of $10-90^{\circ}$. Scanning electron microscopy (SEM, FEI Quanta 3D) was used to observe the surface of samples. A Nicolet 6700 FT-IR spectrometer (Thermo Scientific) with attenuated total reflection (ATR) attachment was used to collect IR spectra. The BrunauerEmmett-Teller (BET) surface area and pore size of silica were determined from $\mathrm{N}_{2}$ adsorption measurements. $\mathrm{N}_{2}$ adsorption/desorption isotherms at $77 \mathrm{~K}$ were recorded using Autosorb-1 (Quantachrome, UK) in the range of relative pressures, $\mathrm{P} / \mathrm{P}_{0}$, from 0.005 to 0.991 . Samples were outgassed for $10 \mathrm{~h}$ at $150^{\circ} \mathrm{C}$ prior to measurements to remove any moisture or adsorbed contaminants. The chemical composition of the obtained silica was examined by Xray fluorescence (XRF) using a PANalytical Axios mAX instrument.

\section{Results and discussion}



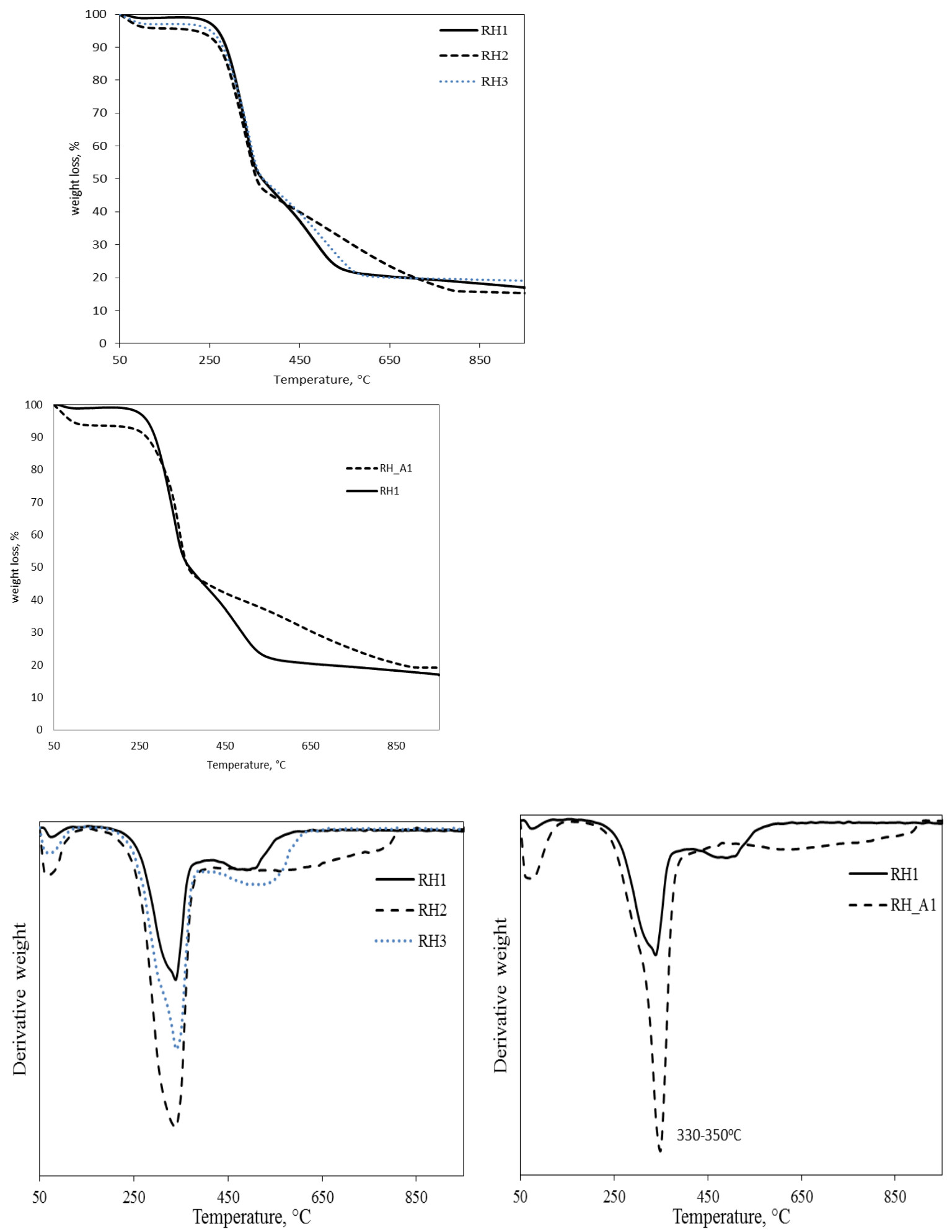

Fig. 2 shows weight losses of RH samples by using TGA analysis. The initial weight loss associated with moisture evaporation occurs within the range of $50-150{ }^{\circ} \mathrm{C}$. The mass loss at temperatures from 210 to $360^{\circ} \mathrm{C}$ is rapid and significant and assigned to the thermal decomposition of hemicellulose and cellulose as a major organic component in the RH (Mor 
et al., 2017). DTG curves show a peak at the range of $330-360^{\circ} \mathrm{C}$ for all samples and the results are similar to those found in the literature for $\mathrm{RH}$ and $\mathrm{RH}$ ash (Santana Costa and Paranhos, 2018). A DTA endothermic peak at $345^{\circ} \mathrm{C}$ is observed when heating cellulose powders under argon atmosphere and it is attributed to its carbonization without combustion (Umeda and Kondoh, 2008). The third mass loss which contributes about $30 \mathrm{wt} . \%$ in a total weight loss starts at $380^{\circ} \mathrm{C}$, differs in a temperature range in all samples and is related to the lignin gradual decomposition between 380 and $600^{\circ} \mathrm{C}\left(800^{\circ} \mathrm{C}\right.$ for $\left.\mathrm{RH} 2\right)$. The thermal profiles of RH1 and 3 are similar and the samples weight is stabilized at temperatures of $560^{\circ} \mathrm{C}$ and above. The differences in thermal profile of $\mathrm{RH} 2$ are attributed to the differences in rice variety, as well as in soil/climate area of growth. The stabilization of mass loss for RH1 and $\mathrm{RH} 3$ samples at $560^{\circ} \mathrm{C}$ indicates the complete burnout of the volatile components and suggests the temperature of about $600^{\circ} \mathrm{C}$ under air atmosphere for sample calcination. The residual masses of samples are: 15.3 (RH2), 17.04 (RH1) and 19.08 wt.\% for RH3. The selected calcination temperature has been used in other studies as well (Mor et al., 2017).
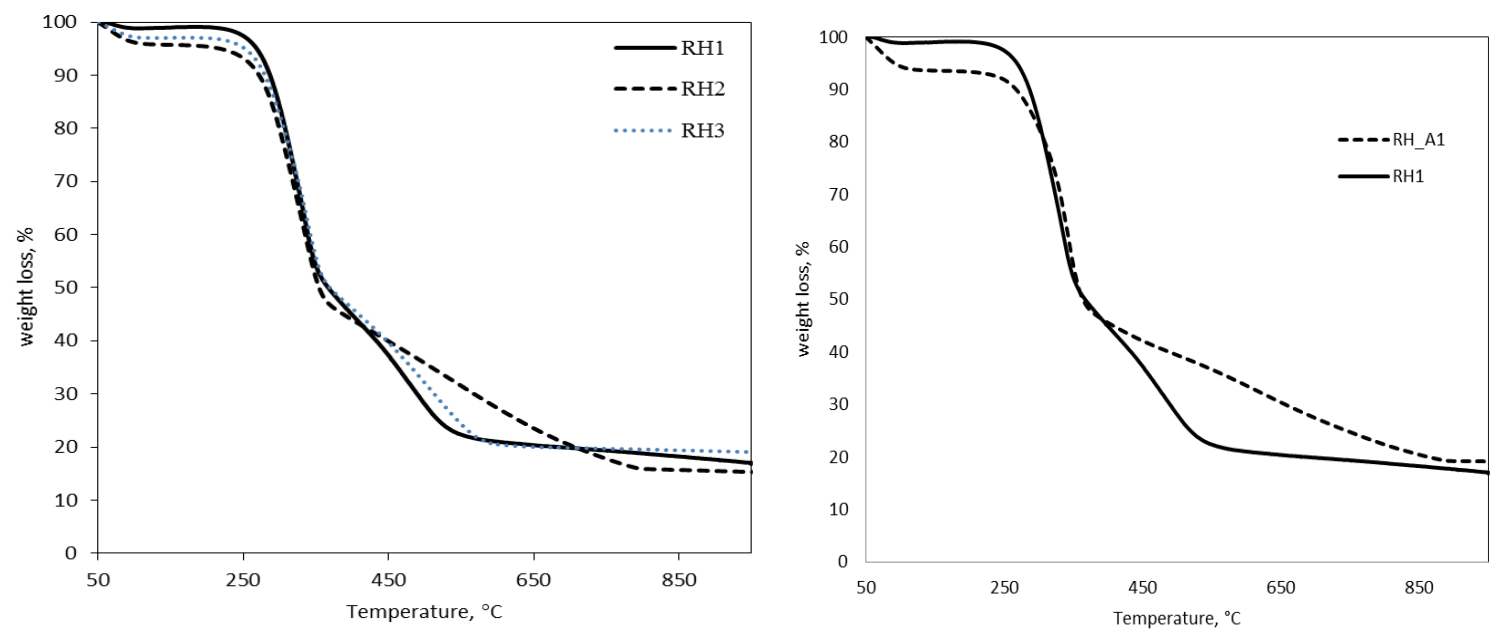



Fig.2. TGA curves for RH1, RH2 and RH3 (upper left) and comparison of TGA of RH1 and RH_A1 (upper right) and corresponding DTG curves for RH1, RH2 and RH3 (lower left) and comparative DTG graph of RH1 and RH_A1 (lower right) samples.

Stoichiometric quantities of $\mathrm{WRH}, \mathrm{NaOH}$ and $\mathrm{HCl}$ were used for silica precipitation. The process involves two-steps, alkali solubilization and acid precipitation:

$$
\begin{gathered}
2 \mathrm{NaOH}+x \mathrm{SiO}_{2} \rightarrow \mathrm{Na}_{2} \mathrm{SiO}_{3}+\mathrm{H}_{2} \mathrm{O} \\
\mathrm{Na}_{2} \mathrm{SiO}_{3}+2 \mathrm{HCl} \rightarrow \mathrm{SiO}_{3}(\text { gel }) \downarrow+2 \mathrm{NaCl}+\mathrm{H}_{2} \mathrm{O}
\end{gathered}
$$

The treatment of alkaline solubilizate with hydrochloric acid promotes silanol $\left(\mathrm{R}_{3} \mathrm{Si}-\right.$ $\mathrm{OH})$ groups formation and condensation that leads to the formation of extended threedimensional $\mathrm{Si}-\mathrm{O}-\mathrm{Si}$ network. The XRD diffraction spectra of $\mathrm{RH}_{-} 2$ and $\mathrm{SiO}_{2} \_\mathrm{T} 2$ sample obtained from WRH is shown in Fig.3. The peaks $15.4^{\circ}, 21^{\circ}$ and $34^{\circ}$ of the $\mathrm{RH}$ fully correspond to cellulose $\mathrm{I}$. The observed broad halo $\left(\mathrm{SiO}_{2} \_\mathrm{T} 2\right)$ with maximum intensity at $2 \theta=22^{\circ}$ confirms the amorphous structure of obtained silica (Kalapathy et al., 2001) and corresponds to the d-spacing value of $0.36 \mathrm{~nm}$. The XRD patterns of other silica samples obtained confirm the absence of any ordered crystalline structure. As it is well known, acid pretreatment affects the chemical composition of the $\mathrm{RH}$ derived products, but not their structure, i.e. whether crystalline or amorphous; the type of silica is determined by the calcination temperature and crystalline forms are produced above $700-900^{\circ} \mathrm{C}$ (Ugheoke and Mamat, 2012). 


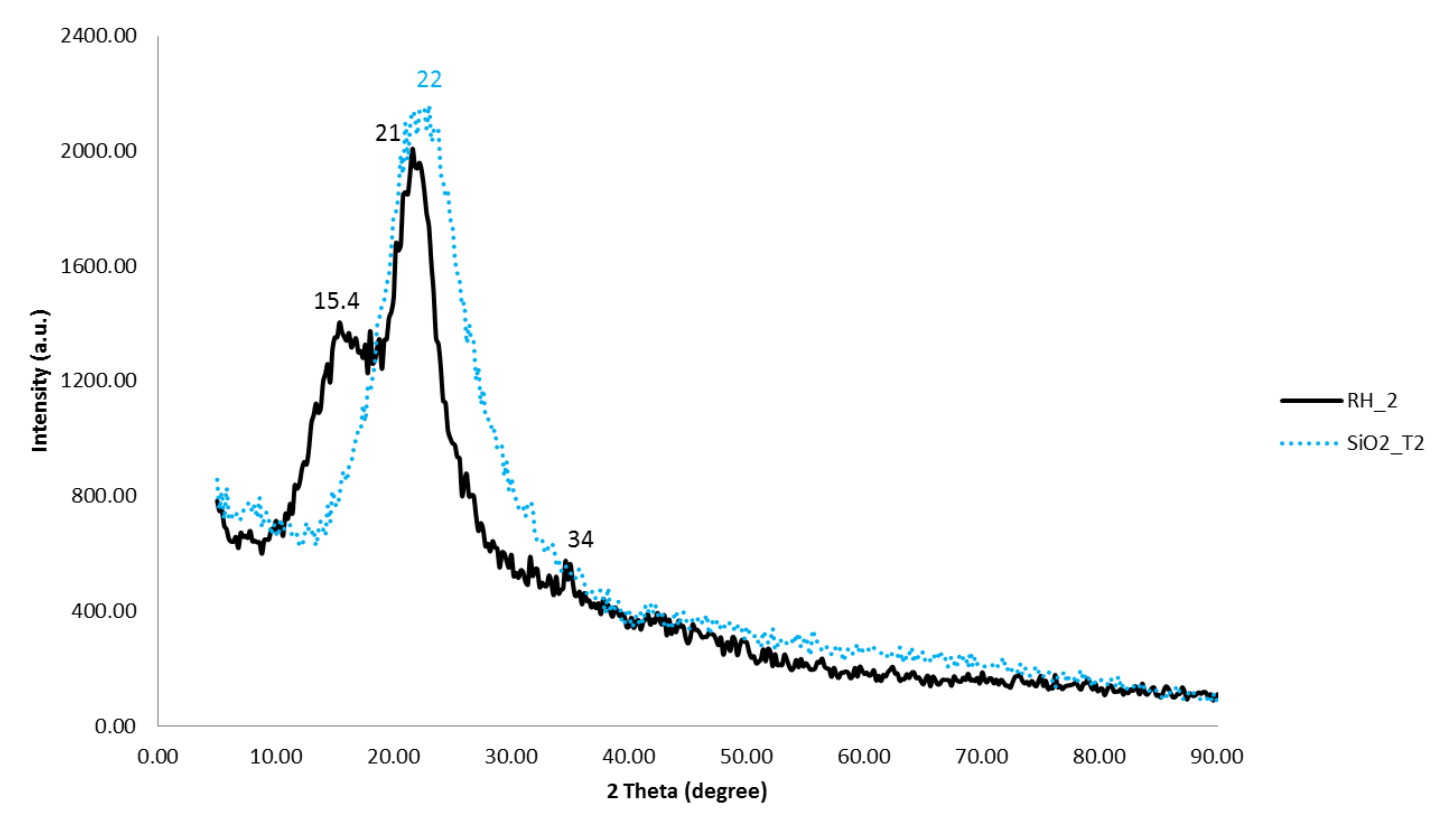

Fig.3. X-ray diffraction pattern of $\mathrm{RH}_{-} 2$ and $\mathrm{SiO}_{2} \_\mathrm{T} 2$ sample.

According to the SEM results (Fig.4), the untreated sample shows a structural network typical of $\mathrm{RH}$ (Patel et al., 1987), this of $\mathrm{HCl}$ pre-treated sample has significant structure breakdown due to acid delignification and the silica precipitate obtained from $\mathrm{HCl}$ pre-treated RH shows that is fully transformed into amorphous nanomaterial with particle size of about $50 \mathrm{~nm}$.

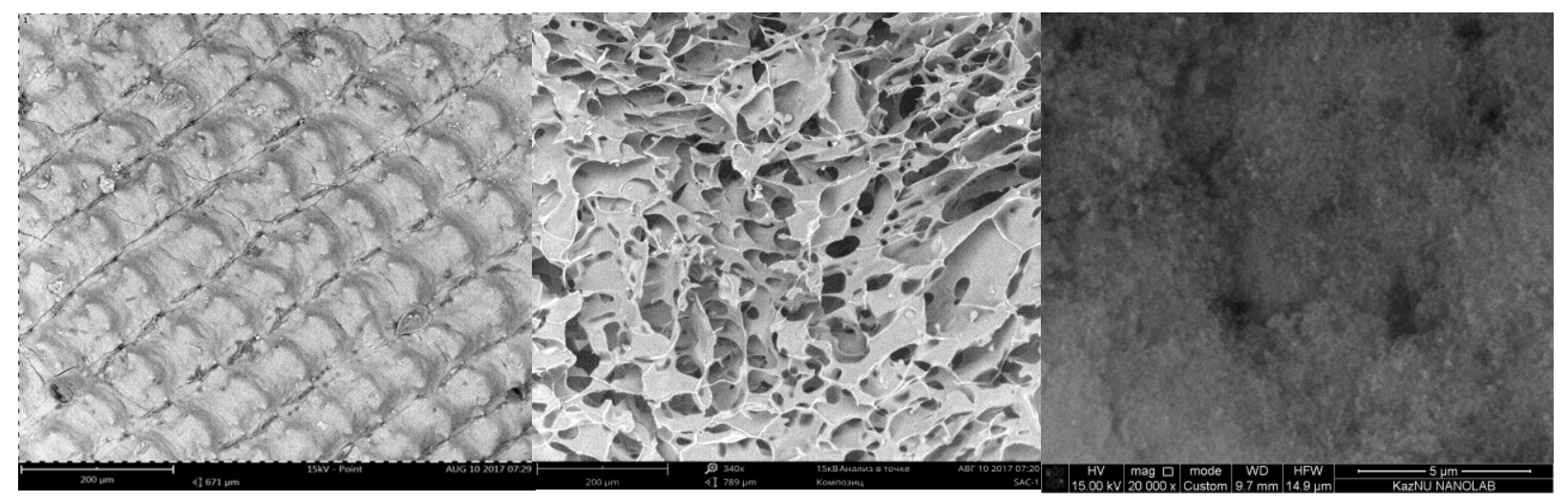

Fig.4. SEM images of untreated RH1(left), $\mathrm{RH}_{-} \mathrm{A} 1$ (middle) and SiO2_A1 (right). SEM images of silica samples obtained from non-pre-treated and citric acid pre-treated RH are shown in Fig.5. Silica precipitates show a nanoscale roughness which comes from the amorphous morphology of silica nanoparticles, dispersed within the bulk phase. 

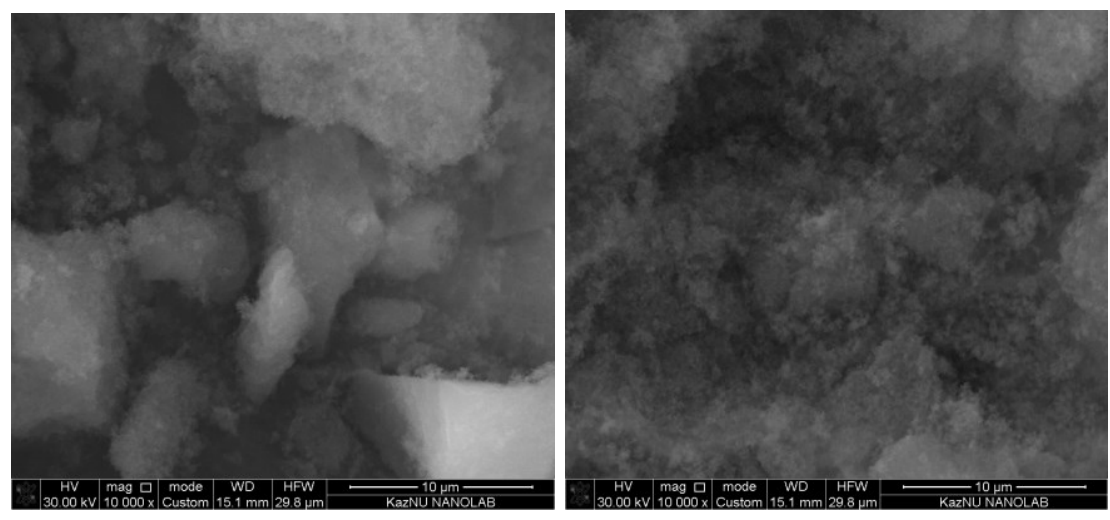

Fig.5. SEM images of $\mathrm{SiO}_{2} \mathrm{~T}_{1}$ (left), $\mathrm{SiO}_{2} \_\mathrm{CA} 1$ (right) samples.

The effects of acid pre-treatment were investigated by TGA analysis. TGA curves for

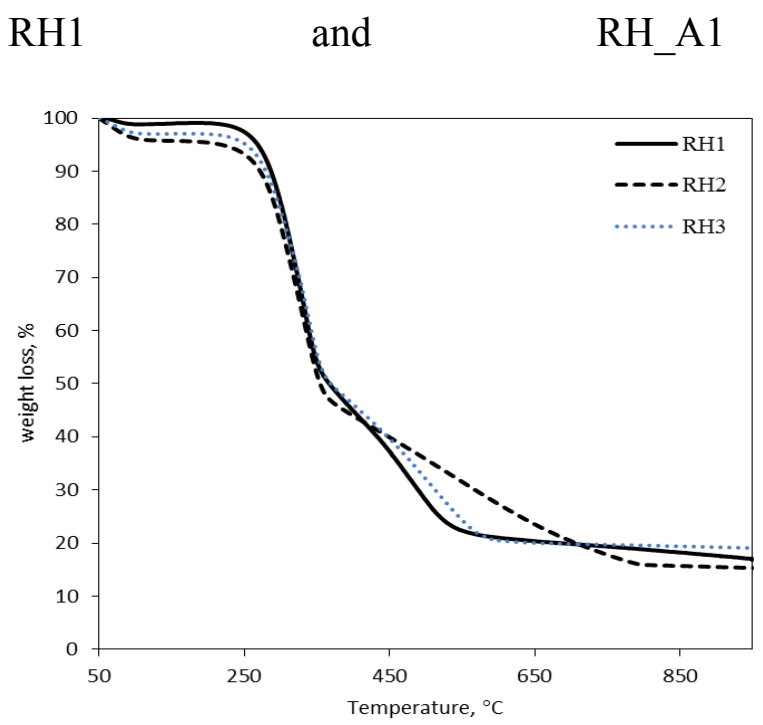

are

given

in
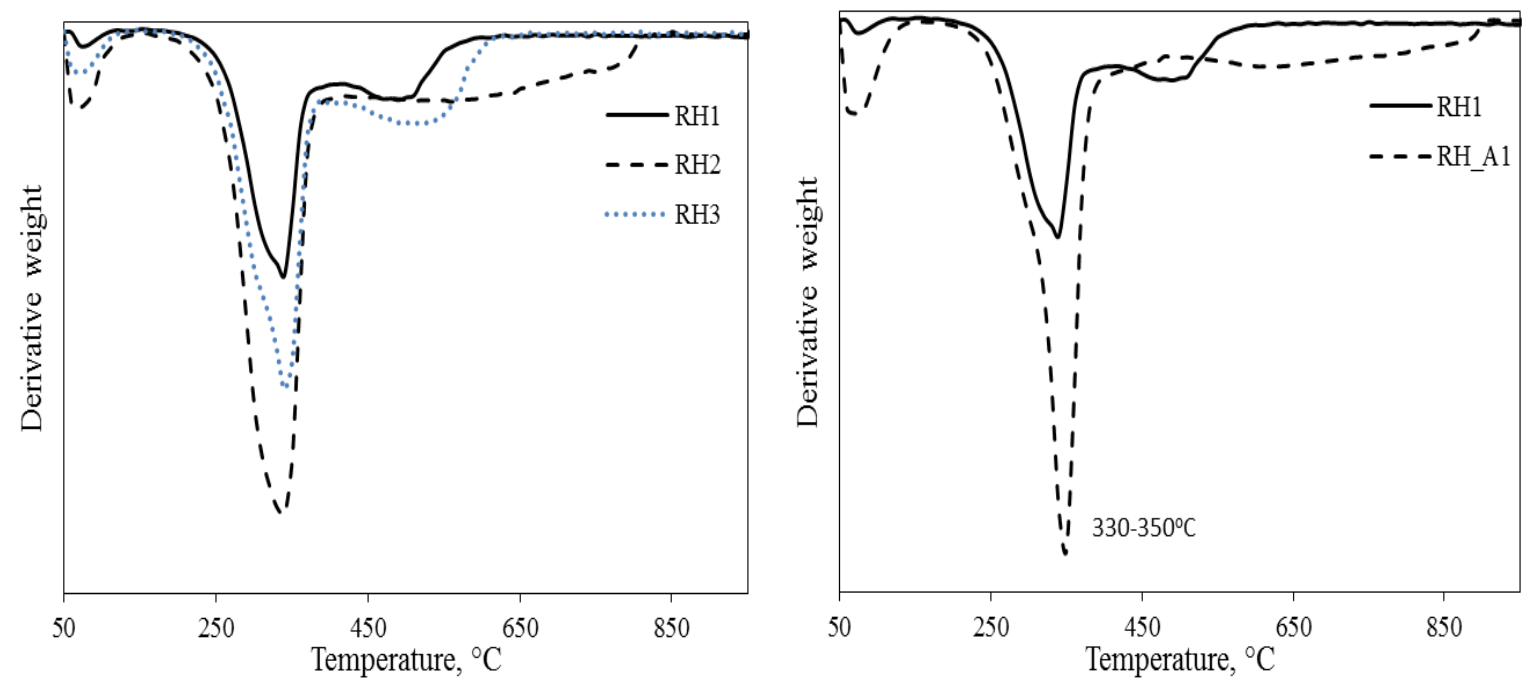
Fig.2. The first weight loss in RH_A1 sample occurred near $100^{\circ} \mathrm{C}$, which is associated with the evaporation of water. The hemicellulose and cellulose thermal decomposition started at $220{ }^{\circ} \mathrm{C}$ and the lignin decomposition occurred beyond $400{ }^{\circ} \mathrm{C}$. The results show less than $3 \%$ difference of the total mass loss between the treated and untreated samples.

The functional groups present in $\mathrm{RHs}$ and $\mathrm{SiO}_{2}$ precipitate were identified by FTIR-ATR spectra (Fig.6).
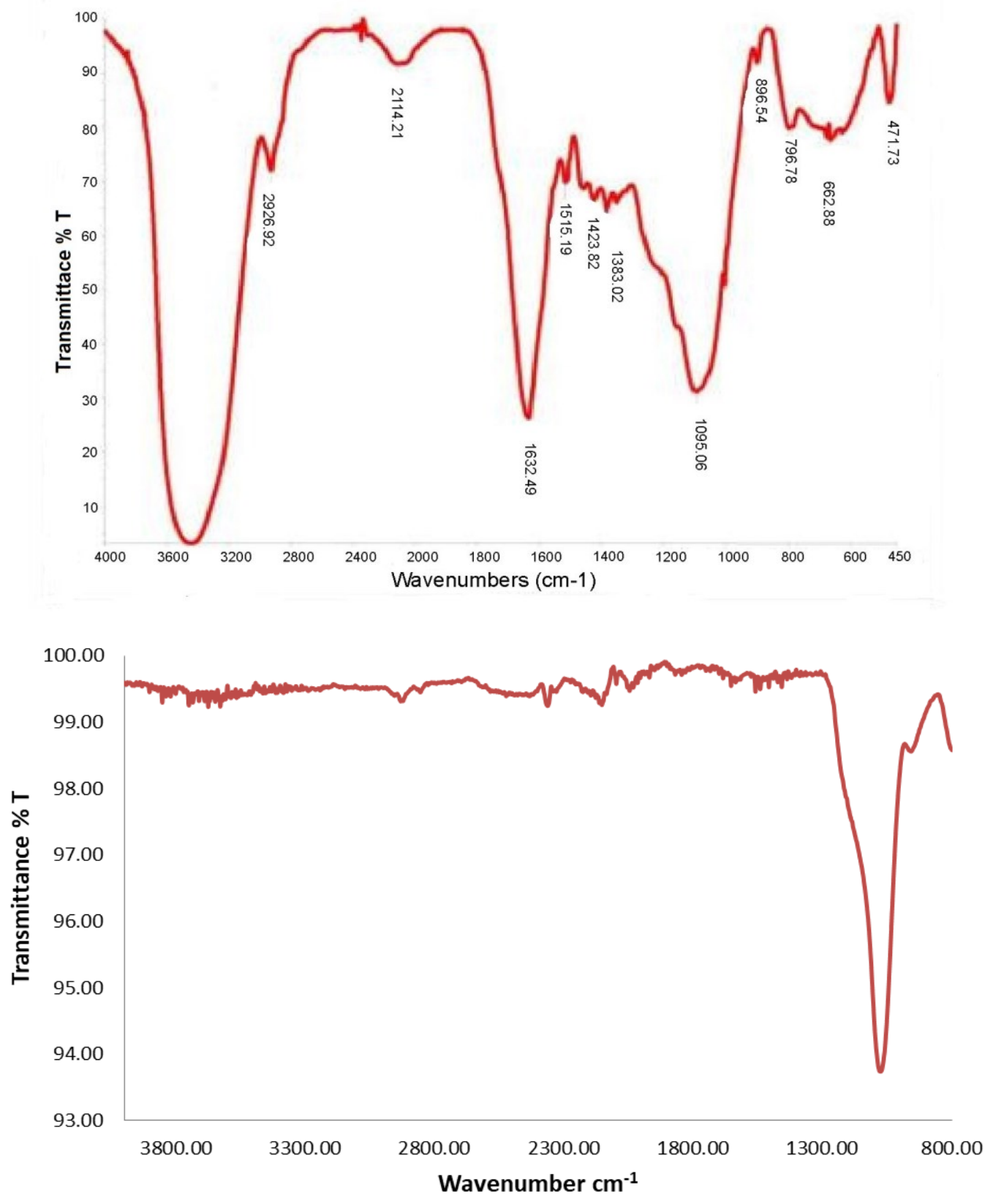

Fig.6. FTIR spectra of RH (top) and $\mathrm{SiO}_{2} \mathrm{~T} 1$ (bottom). 
The broad peak in Fig.6 (top) at about $3500 \mathrm{~cm}^{-1}$ corresponds to the $-\mathrm{O}-\mathrm{H}$-stretching vibrations of water molecules. The absorption peak at $2926 \mathrm{~cm}^{-1}$ can be attributed to the symmetric and asymmetric stretching vibrations of the aliphatic $\mathrm{C}-\mathrm{H}$ bonds in $-\mathrm{CH}_{3}$ and $\mathrm{CH}_{2}$ groups in the structures cellulose, hemicellulose and lignin, respectively and 2114, 1423 and $1383 \mathrm{~cm}^{-1}$ are related to the $-\mathrm{C}-\mathrm{H}$ stretching vibrations of the methylene groups. The peak at $1632 \mathrm{~cm}^{-1}$ can be attributed to the $-\mathrm{C}=\mathrm{O}$ stretching vibrations of the carbonyl groups in aldehydes and ketones. The peak at $1515 \mathrm{~cm}^{-1}$ corresponds to the $-\mathrm{C}-\mathrm{O}$ groups stretching of carboxylates. The broad peaks at 1095, 898, 796, 662 and $471 \mathrm{~cm}^{-1}$ are attributed to the stretching vibrations of the siloxane groups. The notable absorption peak in Fig. 6 (bottom) at $1055 \mathrm{~cm}^{-1}$ can be attributed to the siloxane ( $\mathrm{Si}-\mathrm{O}-\mathrm{Si}$ ) network vibration modes, indicating a highly condensed silica network (Meléndez-Ortiz et al., 2014) and is in agreement with the literature (Umeda and Kondoh, 2010). The spectras of the produced $\mathrm{SiO}_{2}$ show no other band attributed to organic or inorganic impurities.

Table 3

Gas porosimetry analysis (BET and DFT methods)

\begin{tabular}{|c|c|c|c|}
\hline Sample & $\begin{array}{c}\text { Surface area } \\
\left(\mathrm{m}^{2} / \mathrm{g}\right)\end{array}$ & $\begin{array}{l}\text { Pore volume } \\
\qquad\left(\mathrm{cm}^{3} / \mathrm{g}\right)\end{array}$ & $\begin{array}{c}\text { Pore width (mode) } \\
(\mathrm{nm})\end{array}$ \\
\hline & BET method & DFT method & DFT method \\
\hline $\mathrm{SiO}_{2} \mathrm{~T} 1$ & 115 & 0.49 & 25.5 \\
\hline $\mathrm{SiO}_{2} \mathrm{~T} 2$ & 630 & 0.77 & 1.07 \\
\hline $\mathrm{SiO}_{2} \mathrm{~T}_{3}$ & 160 & 0.76 & 15.3 \\
\hline $\mathrm{SiO}_{2}{ }_{\mathrm{A}} \mathrm{l}$ & 120 & 0.50 & 26.4 \\
\hline $\mathrm{SiO}_{2} \_\mathrm{A} 2$ & 980 & 1.20 & 0.98 \\
\hline $\mathrm{SiO}_{2} \_\mathrm{A} 3$ & 150 & 0.75 & 18.4 \\
\hline
\end{tabular}




\begin{tabular}{lccc}
\hline $\mathrm{SiO}_{2} \mathrm{CA} 1$ & 112 & 0.48 & 25.6 \\
$\mathrm{SiO}_{2} \mathrm{C} A 2$ & 625 & 0.77 & 1.62 \\
$\mathrm{SiO}_{2} \mathrm{CA} 3$ & 174 & 0.76 & 17.3 \\
\hline
\end{tabular}

The surface area (BET) of the samples is shown in Table 3, the nitrogen adsorption/desorption isotherms in Fig.7a,b,c and the pore size distribution in Fig 8. The BET surface area of the RH1 and RH3-derived materials is between 115 and $174 \mathrm{~m}^{2}$, lower than those reported in the literature, for instance $198-212 \mathrm{~m}^{2} / \mathrm{g}$ (He et al., 2014), 174-294 $\mathrm{m}^{2} / \mathrm{g}$ (Santana Costa and Paranhos, 2018), 208-218 $\mathrm{m}^{2} / \mathrm{g}$ (Bakar et al., 2016) and 220-313 $\mathrm{m}^{2} / \mathrm{g}$ (Alyosef et al., 2013) for several acid-treated derived samples. However, the RH2-derived material has much higher surface area of all the reported ones between 625 and $980 \mathrm{~m}^{2} / \mathrm{g}$. This demonstrates the variability of raw $\mathrm{RH}$ which leads to products of different properties. The isotherms of $\mathrm{SiO}_{2} \mathrm{~A} 1$ and $\mathrm{SiO}_{2} \mathrm{~A} 3$ samples are closer to type III with a weak hysteresis loop and curvature in low pressures indicating mesoporous-macroporous materials. The isotherm of $\mathrm{SiO}_{2}$ A2 sample is closer to type II with a more intense hysteresis loop and curvature in low pressures indicating a mesoporous-macroporous material with some microporosity, similar to the isotherms derived elsewhere (Alyosef et al., 2013). These conclusions are supported by the pore volume and average pore size (Table 3) and the pore size distribution of samples (Fig. 8). Thus, it seems that the RH2-derived samples exhibit major pore structure differences in comparison to RH1 and RH3 derived samples. 

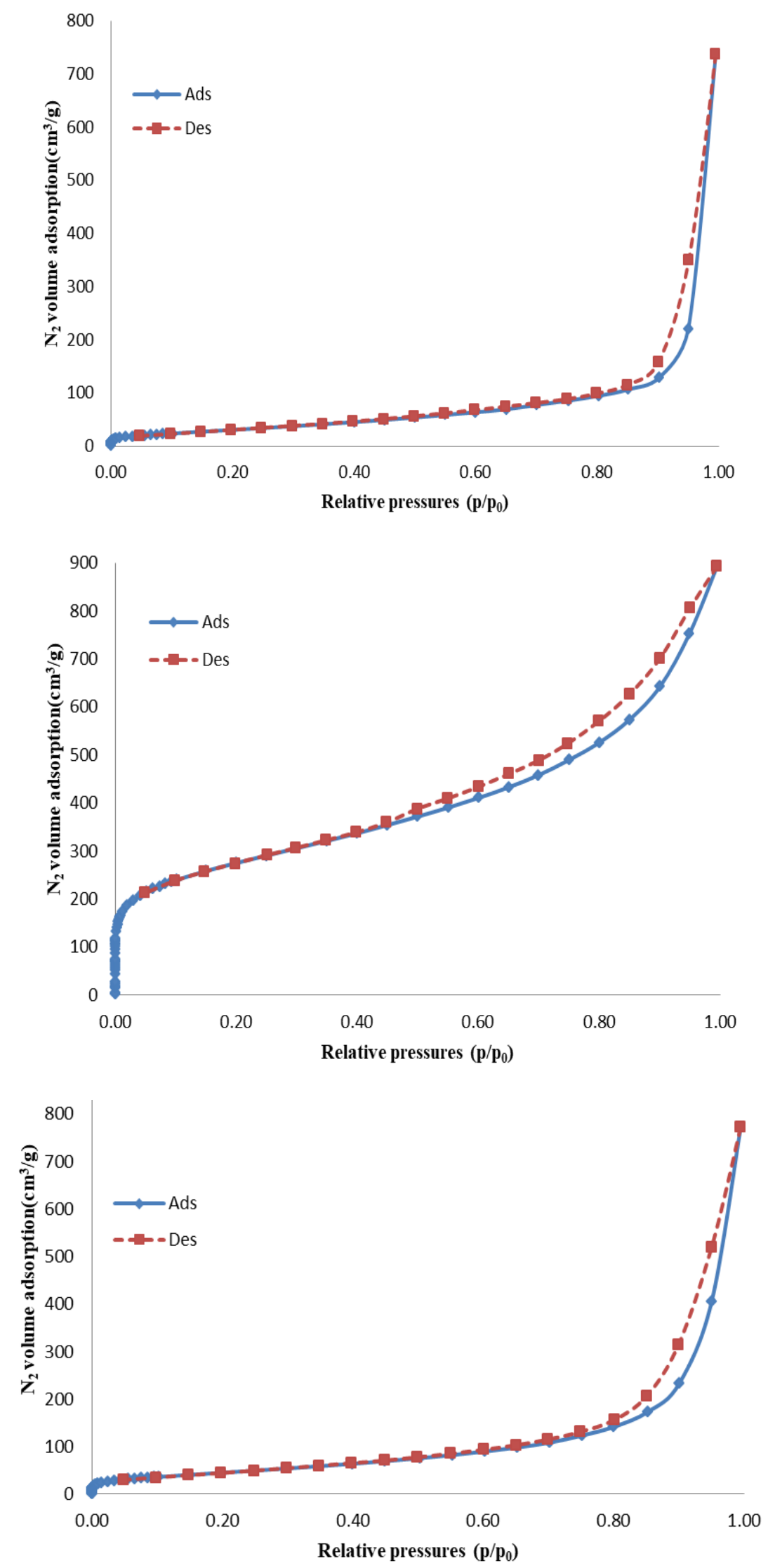

Fig.7. Low temperature nitrogen adsorption on $\mathrm{SiO}_{2} \_\mathrm{A} 1$ (top), $\mathrm{SiO}_{2} \_\mathrm{A} 2$ (middle) and

$$
\mathrm{SiO}_{2} \mathrm{~A} 3 \text { (bottom) }
$$




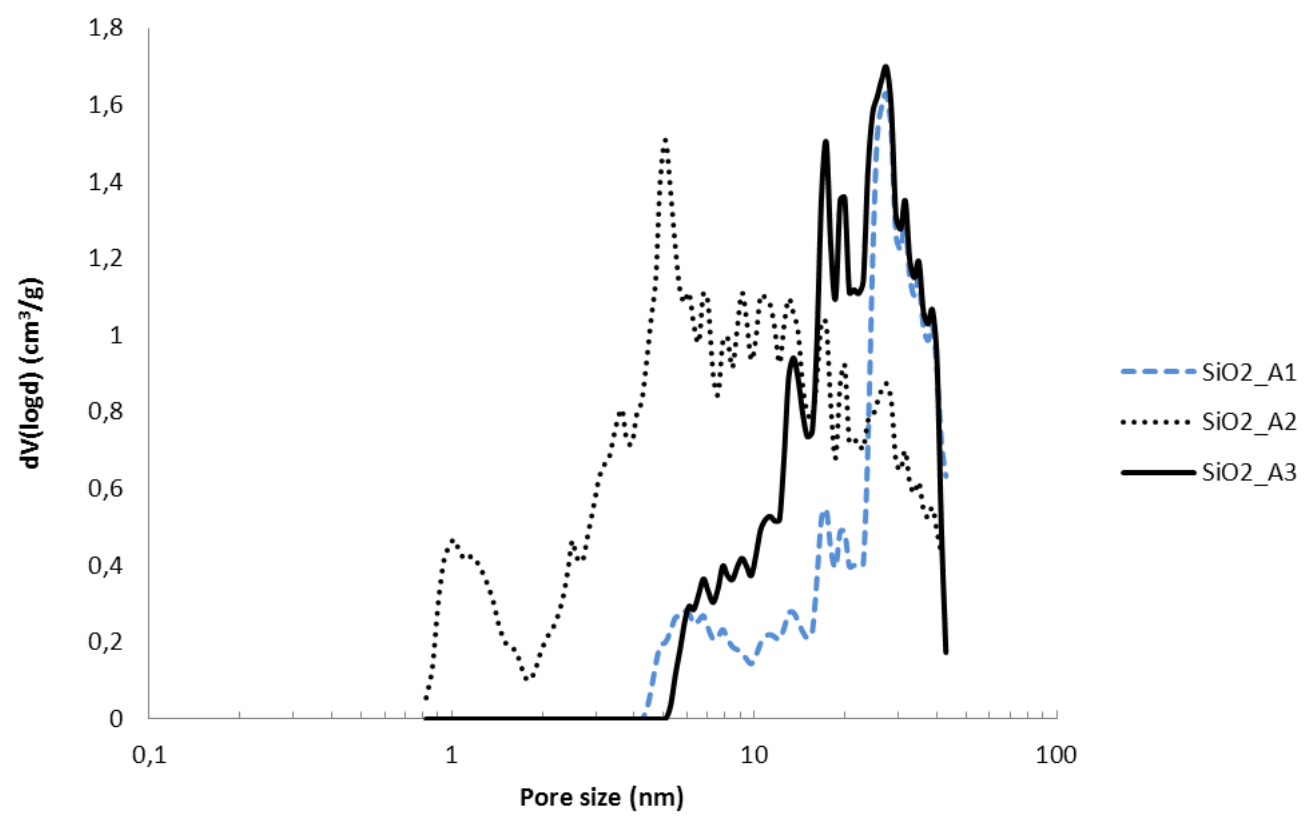

Fig.8. Pore size distribution of $\mathrm{SiO}_{2} \mathrm{~A} 1, \mathrm{SiO}_{2} \_\mathrm{A} 2$ and $\mathrm{SiO}_{2} \mathrm{~A} 3$

In Table 4, the XRF results show that $\mathrm{SiO}_{2}$ is a major component of the siliceous precipitate and the content of metal impurities is low.

\section{Table 4}

Results of XRF analysis of silica samples

\begin{tabular}{|c|c|c|c|c|c|c|c|c|c|}
\hline \multirow{2}{*}{ Composition } & \multicolumn{9}{|c|}{ Sample name } \\
\hline & $\mathrm{SiO}_{2} \mathrm{~T} 1$ & $\mathrm{SiO}_{2} \mathrm{~T} 2$ & $\mathrm{SiO}_{2} \_\mathrm{T} 3$ & $\mathrm{SiO}_{2} \_\mathrm{A} 1$ & $\mathrm{SiO}_{2} \mathrm{~A} 2$ & $\mathrm{SiO}_{2} \_\mathrm{A} 3$ & $\mathrm{SiO}_{2} \mathrm{CA}_{1}$ & $\mathrm{SiO}_{2} \mathrm{CA}_{2}$ & $\mathrm{SiO}_{2} \mathrm{CA} 3$ \\
\hline $\mathrm{SiO}_{2}$ & 95.60 & 84.81 & 88.91 & 98.21 & 99.07 & 99.67 & 94.58 & 98.67 & 92.44 \\
\hline $\mathrm{Cl}$ & 1.979 & 10.327 & 7.941 & 1.792 & 0.791 & - & 2.336 & 0.783 & 3.495 \\
\hline $\mathrm{Zn}$ & 0.046 & 0.066 & - & - & 0.122 & 0.047 & - & 0.026 & 1.448 \\
\hline $\mathrm{Fe}$ & 0.390 & 0.445 & 0.069 & - & 0.020 & 0.001 & 0.265 & 0.169 & 0.104 \\
\hline $\mathrm{K}$ & 0.698 & 1.768 & 1.044 & - & - & 0.087 & 1.525 & 0.133 & 1.904 \\
\hline $\mathrm{Ca}$ & 1.141 & 1.242 & 0.134 & - & - & 0.200 & 0.629 & 0.107 & 0.103 \\
\hline $\mathrm{Mn}$ & 0.018 & 0.009 & - & & & & 0.063 & 0.100 & 0.111 \\
\hline
\end{tabular}


In Fig.9 for all studied samples the WRH yield varies slightly between 14.9 and $20 \mathrm{wt} . \%$, but it is noteworthy that the acid pre-treatment intensifies the $\mathrm{SiO}_{2}$ yield from the $\mathrm{RH}$. The eco-friendly citric acid pre-treatment increases the purity of the precipitate silica sample compared to the directly calcinated. The purity mean values of silica samples obtained via different methods range from 84.81 to 99.66 wt.\%. The developed method of citric acid pretreatment is eco-friendly compared with the conventional one and has promising potential, as it showed high purity silica.

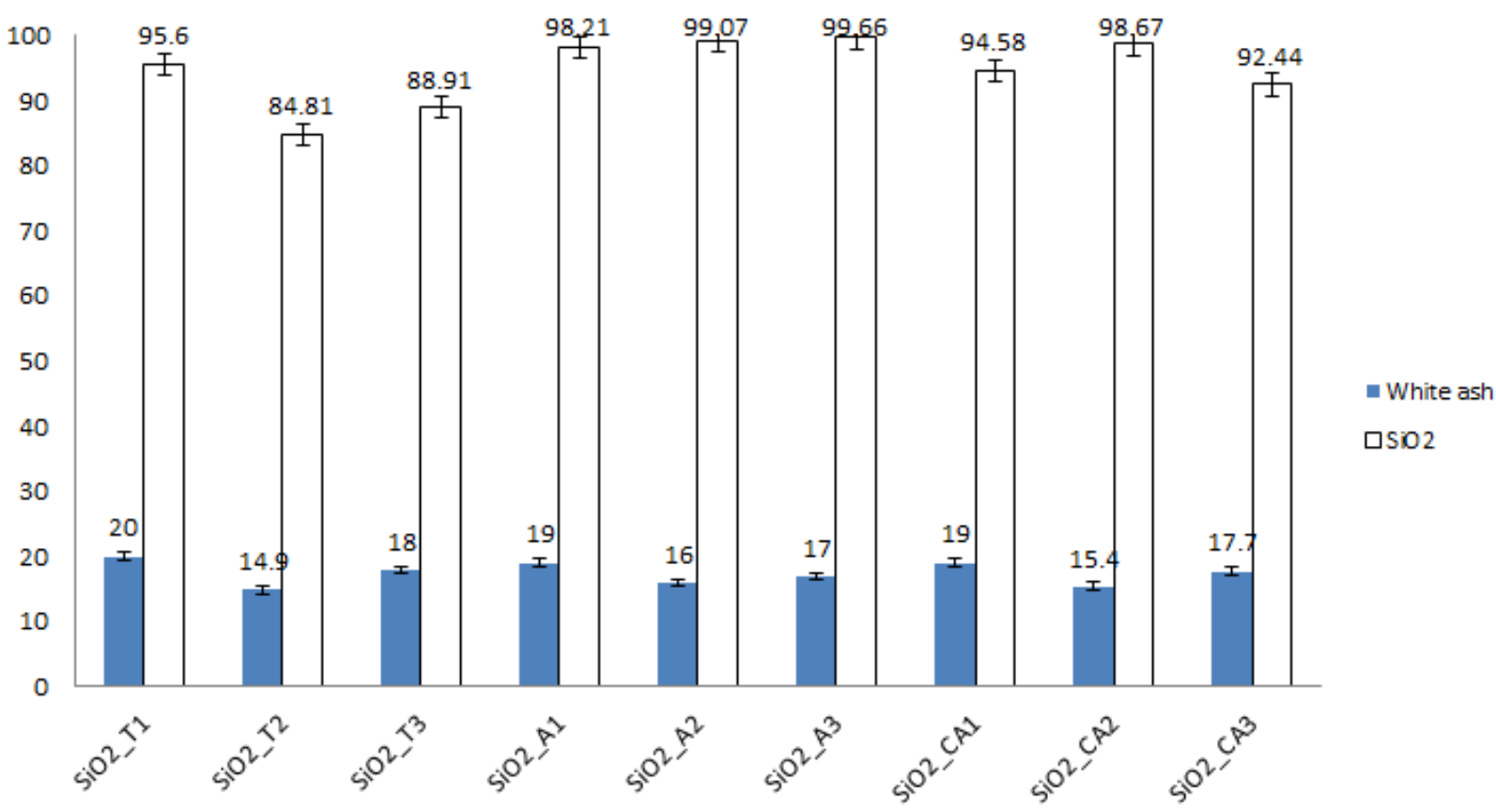

Fig.9. Yield of WRH and content of silica in wt.\%.

Considering the yield of highly pure amorphous silica produced via the three methods examined in this work, the production of silica from RH can be a significant source of wealth for the regional economy of the rice-growing districts of Kazakhstan. The projected output of 2,561 t of WRH in Kazakhstan annually can have significant implication on the financial stability of the regional communities. The development of small plants for silica production from RH may create workplaces in predominantly agricultural communities, but also solve the management problem of this specific agricultural waste stream. The use of citric acid in the process line makes the production cleaner in comparison with the conventional method, 
as the organic acid used for acidification of the RH decompose during calcination, whereas inorganic acids $\left(\mathrm{HCl}, \mathrm{H}_{2} \mathrm{SO}_{4}, \mathrm{H}_{3} \mathrm{PO}_{4}\right.$ etc.) produced after washing of the materials must be neutralized. Based on the amount of reagents needed $(670 \mathrm{ml}$ of $37 \% \mathrm{HCl}$ and $100 \mathrm{~g} / \mathrm{kg}$ of $\mathrm{RH})$ and the whole sale prices of $\mathrm{HCl}(37 \%)(\$ 200 / \mathrm{t})$ and citric acid $(\$ 600 / \mathrm{t})$, the greener process is proven to be cheaper as well, without taking into account the $\mathrm{NaOH}$ cost needed for neutralization ( $\$ 350 / \mathrm{t}$ of flakes) and the corrosion problems due to the use of strong acids and bases.

\section{Conclusions}

Amorphous silica with purity as high as $99.96 \%$, yield of $20 \%$ and surface area of 980 $\mathrm{m}^{2} / \mathrm{g}$ was synthesized by using $\mathrm{RH}$ from different regions of Kazakhstan. The effects of inorganic and organic acid pre-treatment and pyrolysis temperature on silica purity were evaluated by TGA/DTA. The TGA results show significant changes in the pyrolysis behavior of $\mathrm{RH}$ after acid pre-treatment, which increases the organic removal efficiencies during the calcination process. A novel dry citric acid pre-treatment is presented that exhibits environmental and economic advantages over the traditional $\mathrm{HCl}$ pre-treatment. The results showed that the direct thermal treatment of $\mathrm{RH}$ is a chemical- and labor-saving procedure, but the produced silica is of low purity, reaching a maximum of $95.6 \%$. The characterization of the derived materials showed variation, especially in the surface area, ranging from 112 to $980 \mathrm{~m}^{2} / \mathrm{g}$. Although hydrochloric acid pre-treatment resulted in higher purity products, citric acid treatment was proven to be competitive due to the high purity obtained (98.67\%), the lower cost and the reduced environmental impact.

\section{Acknowledgements}


This research was financially supported by the Nazarbayev University ORAU project "Hyperstiochiometry Activity in Metal Nanoparticle Interaction (HYPERActiv)", SOE 2015 009.

\section{References}

Alyosef, H.A., Eilert, A., Welscher, J., Ibrahim, S.S., Denecke, R., Schwieger, W., Enke, D., 2013. Characterization of biogenic silica generated by thermo chemical treatment of rice husk. Part. Sci. Technol. 31, 524-532. https://doi.org/10.1080/02726351.2013.782931

Ang, T.N., Ngoh, G.C., Chua, A.S.M., 2013. Comparative study of various pretreatment reagents on rice husk and structural changes assessment of the optimized pretreated rice husk. Bioresour. Technol. 135, 116-119. https://doi.org/10.1016/j.biortech.2012.09.045

Bakar, R.A., Yahya, R., Gan, S.N., 2016. Production of High Purity Amorphous Silica from Rice Husk. Procedia Chem. 19, 189-195. https://doi.org/10.1016/j.proche.2016.03.092

Chen, X., Hadde, E., Liu, S., Peng, Y., 2017. The effect of amorphous silica on pulp rheology and copper flotation. Miner. Eng. 113, 41-46. https://doi.org/10.1016/j.mineng.2017.08.001

Feng, Q., Lin, Q., Gong, F., Sugita, S., Shoya, M., 2004. Adsorption of lead and mercury by rice husk ash. J. Colloid Interface Sci. 278, 1-8.

https://doi.org/10.1016/j.jcis.2004.05.030

Fernandes, I.J., Calheiro, D., Sánchez, F.A.L., Camacho, A.L.D., Rocha, T.L.A. de C., Moraes, C.A.M., Sousa, V.C. de, 2017. Characterization of Silica Produced from Rice Husk Ash: Comparison of Purification and Processing Methods. Mater. Res. 20, $512-$ 518. https://doi.org/10.1590/1980-5373-mr-2016-1043

Franco, D.S.P., Tanabe, E.H., Bertuol, D.A., Dos Reis, G.S., Lima, É.C., Dotto, G.L., 2017. Alternative treatments to improve the potential of rice husk as adsorbent for methylene 
blue. Water Sci. Technol. 75, 296-305. https://doi.org/10.2166/wst.2016.504

He, J.R., Kuo, W.C., Su, C.S., Lin, H.P., 2014. Isolation of bio-mesoporous silica from rice husk. J. Chinese Chem. Soc. 61, 836-840. https://doi.org/10.1002/jccs.201300658

Kalapathy, U., Proctor, A., Shultz, J., 2001. A simple method for production of pure silica from rice hull ash. Fuel Energy Abstr. 42, 45. https://doi.org/10.1016/S01406701(01)80487-2

Kannan, V., 2018. Strength and durability performance of self compacting concrete containing self-combusted rice husk ash and metakaolin. Constr. Build. Mater. 160, 169-179. https://doi.org/10.1016/j.conbuildmat.2017.11.043

Kumar, S., Sangwan, P., V, D.R.M., Bidra, S., 2013. Utilization of Rice Husk and Their Ash : A Review. J. Chem. Environ. Sci. 1, 126-129.

Lakshmi, U.R., Srivastava, V.C., Mall, I.D., Lataye, D.H., 2009. Rice husk ash as an effective adsorbent: Evaluation of adsorptive characteristics for Indigo Carmine dye. J. Environ. Manage. 90, 710-720. https://doi.org/10.1016/j.jenvman.2008.01.002

Liu, Y., Guo, Y., Gao, W., Wang, Z., Ma, Y., Wang, Z., 2012. Simultaneous preparation of silica and activated carbon from rice husk ash. J. Clean. Prod. 32, 204-209. https://doi.org/10.1016/j.jclepro.2012.03.021

Meléndez-Ortiz, H.I., Perera-Mercado, Y., Mercado-Silva, J.A., Olivares-Maldonado, Y., Castruita, G., García-Cerda, L.A., 2014. Functionalization with amine-containing organosilane of mesoporous silica MCM-41 and MCM-48 obtained at room temperature. Ceram. Int. 40, 9701-9707. https://doi.org/10.1016/j.ceramint.2014.02.051

Memon, S.A., Shaikh, M.A., Akbar, H., 2011. Utilization of Rice Husk Ash as viscosity modifying agent in Self Compacting Concrete. Constr. Build. Mater. 25, 1044-1048. https://doi.org/10.1016/j.conbuildmat.2010.06.074

Mitran, R.A., Matei, C., Berger, D., Băjenaru, L., Moisescu, M.G., 2018. Controlling drug 
release from mesoporous silica through an amorphous, nanoconfined 1-tetradecanol layer. Eur. J. Pharm. Biopharm. 127, 318-325.

https://doi.org/10.1016/j.ejpb.2018.02.020

Mor, S., Chhoden, K., Ravindra, K., 2016. Application of agro-waste rice husk ash for the removal of phosphate from the wastewater. J. Clean. Prod. 129, 673-680. https://doi.org/10.1016/j.jclepro.2016.03.088

Mor, S., Manchanda, C.K., Kansal, S.K., Ravindra, K., 2017. Nanosilica extraction from processed agricultural residue using green technology. J. Clean. Prod. 143, 1284-1290. https://doi.org/10.1016/j.jclepro.2016.11.142

Ng, E.P., Awala, H., Tan, K.H., Adam, F., Retoux, R., Mintova, S., 2015. EMT-type zeolite nanocrystals synthesized from rice husk. Microporous Mesoporous Mater. 204, $204-$ 209. https://doi.org/10.1016/j.micromeso.2014.11.017

Niyomwas, S., 2009. Synthesis and Characterization of Silicon-Silicon Carbide Composites from Rice Husk Ash via Self-Propagating High Temperature Synthesis. J. Met. Mater. Miner. 19, 21-25.

Patel, M., Karera, A., Prasanna, P., 1987. Effect of thermal and chemical treatments on carbon and silica contents in rice husk. J. Mater. Sci. 22, 2457-2464. https://doi.org/10.1007/BF01082130

Pivovarov, S., 2008. Adsorption of ions onto amorphous silica: Ion exchange model. J. Colloid Interface Sci. 319, 374-376. https://doi.org/10.1016/j.jcis.2007.11.009 Prasad, C.S., Maiti, K.N., Venugopal, R., 2001. Effect of rice husk ash in whiteware compositions. Ceram. Int. 27, 629-635. https://doi.org/10.1016/S0272-8842(01)00010-4 Prasara, J., Gheewala, S.H., 2018. Sustainable utilization of rice husk ash from power plants: A review. J. Clean. Prod. 167, 1020-1028. https://doi.org/10.1016/j.jclepro.2016.11.042 Sandhu, R.K., Siddique, R., 2017. Influence of rice husk ash (RHA) on the properties of self- 
compacting concrete: A review. Constr. Build. Mater. 153, 751-764.

https://doi.org/10.1016/j.conbuildmat.2017.07.165

Santana Costa, J.A., Paranhos, C.M., 2018. Systematic evaluation of amorphous silica production from rice husk ashes. J. Clean. Prod. 192, 688-697. https://doi.org/10.1016/j.jclepro.2018.05.028

Satayeva, A.R., Howell, C.A., Korobeinyk, A.V., Jandosov, J., Inglezakis, V.J., Mansurov, Z.A., Mikhalovsky, S.V., 2018. Investigation of rice husk derived activated carbon for removal of nitrate contamination from water. Sci. Total Environ. 630. https://doi.org/10.1016/j.scitotenv.2018.02.329

Shen, Y., Zhao, P., Shao, Q., 2014. Porous silica and carbon derived materials from rice husk pyrolysis char. Microporous Mesoporous Mater. 188, 46-76. https://doi.org/10.1016/j.micromeso.2014.01.005

Shi, B., Shin, Y.K., Hassanali, A.A., Singer, S.J., 2017. Biomolecules at the amorphous silica/water interface: Binding and fluorescence anisotropy of peptides. Colloids Surfaces B Biointerfaces 157, 83-92. https://doi.org/10.1016/j.colsurfb.2017.05.048

Tang, Q., Wang, T., 2005. Preparation of silica aerogel from rice hull ash by supercritical carbon dioxide drying. J. Supercrit. Fluids 35, 91-94. https://doi.org/10.1016/j.supflu.2004.12.003

Ugheoke, I.B., Mamat, O., 2012. A critical assessment and new research directions of rice husk silica processing methods and properties. Maejo Int. J. Sci. Technol. 6, 430-448.

Umeda, J., Kondoh, K., 2010. High-purification of amorphous silica originated from rice husks by combination of polysaccharide hydrolysis and metallic impurities removal. Ind. Crops Prod. 32, 539-544. https://doi.org/10.1016/j.indcrop.2010.07.002

Umeda, J., Kondoh, K., 2008. Process Optimization to Prepare High-purity Amorphous Silica from Rice Husks via Citric Acid Leaching Treatment $\uparrow$. Trans. JWRI 37, $13-17$. 
